\title{
Carl Borchardt en die Suid-Afrikaanse kerkgeskiedenis
}

J W Hofmeyr

\section{ABSTRACT}

\section{Carl Borchardt and South African church history}

Carl Borchardt was in the first instance a general church historian who specialised in the field of the Early Church. However, born as a South African, he did not only do some research in the field of South African church history but he even partook in some crucial events in modern South African church history. This article attempts to describe and explain his interest and involvement in South African church history.

\section{INLEIDING}

Om van Carl Borchardt en die Suid-Afrikaanse kerkgeskiedenis te praat, klink byna soos ' $n$ contradictio in terminis. Carl Borchardt was by uitstek 'n algemene kerkhistorikus en as klassiek geskoolde en spesialis op die terrein van die Patristiek, oftewel die Vroeë Kerkgeskiedenis, was hy ook uitnemend geskik vir hierdie taak as algemene kerkhistorikus. Trouens, hy is een van die min spesialiste op hierdie terrein in Suid-Afrika en hy het daarom ' $n$ belangrike bydrae gelewer tot die uitbou van hierdie belangrike studieterrein in die Suid-Afrikaanse konteks.

Carl Borchardt het egter nooit vreemd gestaan teenoor die konteks waaruit hy voortgekom het en waarin hy uiteindelik ook gefunksioneer het nie. In hierdie oorsig oor Borchardt se betrokkenheid by die SuidAfrikaanse kerkgeskiedenis sal eerstens gefokus word op 'n kort biografiese oorsig oor sy lewe en verbondenheid aan Suid-Afrika, en tweedens op sy visie en arbeid op die terrein van die Suid-Afrikaanse kerkgeskiedenis. Uit hierdie oorsig blyk dit duidelik dat Borchardt verteenwoordiger van 'n oorgangsgeslag kerkhistorici in Suid-Afrika was. Diepgaande teoretiese probleme rondom die kerkhistoriese wetenskap het hy nie dikwels aangespreek nie. Alhoewel hy die feite sterk laat spreek het in sy kerkgeskiedenisbeoefening het hy egter ook teologies interpretatief daarmee omgegaan - hy wou dus baie bepaald as kerkhistorikus en bekwame vakman ook teoloog wees. 


\section{CARL BORCHARDT SE VERBONDENHEID AAN SUID- AFRIKA}

Carl Borchardt was enersyds kind van Suid-Afrika, maar andersyds ook betrokkene by Suid-Afrika met sy probleme en uitdagings. In die beskeie sin van die woord het Borchardt dus self ook 'n stuk Suid-Afrikaanse kerkgeskiedenis help maak.

Carl Frederick August Borchardt is op 25 April 1934 in Germiston gebore waarna hy in 1951 matrikuleer aan die Afrikaanse Hoërskool in Germiston. Vanaf 1952 begin hy sy tersiêre opleiding aan die Universiteit van Pretoria. In 1954 behaal hy die BA-graad, in 1957 die BD-graad en in 1960 die MA-graad in Grieks en Latyn aan sy alma mater. Hierna vertrek hy na Nederland waar hy in 1966 die ThD-graad in Kerkgeskiedenis aan die Rijksuniversiteit van Leiden onder die promotorskap van die bekende professor J N Bakhuizen van den Brink verwerf.

Tussen 1966 en 1969 bedien hy die Nederduits Gereformeerde Gemeente Benoni-Oos en vanaf 1970 word hy seniorlektor in Kerkgeskiedenis aan die Universiteit van Suid-Afrika. Aan die begin van 1976 word hy bevestig as seniorlektor in die departement Kerkgeskiedenis en Kerkreg aan die Fakulteit Teologie (Afdeling B) aan die Universiteit van Pretoria en vanaf September 1976 word hy bevorder tot medeprofessor. In 1986 word hy bevorder tot volle professor en in 1989 tot departementshoof van die Departement Kerkgeskiedenis en Kerkreg in die plek van P B van der Watt. In die loop van hierdie tyd het 'n groot aantal artikels en publikasies uit sy pen verskyn en is hy lid van verskeie plaaslike en internasionale vakverenigings en organisasies ${ }^{1}$.

Carl Borchardt het nie net bydraes tot die Suid-Afrikaanse Kerkgeskiedenis gelewer nie, maar hy was ook betrokkene by die SuidAfrikaanse kerkgeskiedenis. Waarskynlik was twee van sy belangrikste bydraes op hierdie terrein sy betrokkenheid by die Hervormingsdaggetuienis en die Nasionale Inisiatief vir Versoening (NIV).

Op 31 Oktober 1980 word die Hervormingsdaggetuienis van agt vooraanstaande teoloë van die Ned Geref Kerk die wêreld ingestuur. In meer as een opsig was die bekendmaking van die veelbesproke Hervormingsdaggetuienis 'n belangrike gebeurtenis in die Suid-Afrikaanse kerkgeskiedenis. Dit het duidelike roeringe en spanninge in kerklike geledere teweeggebring. Dat die Hervormingsdaggetuienis nie as 'n losstaande gebeurtenis gesien kan word nie, is duidelik. Die publikasie van die Getuienis is voorafgegaan deur 'n taamlike landwye gevoel van besorgdheid in Ned Geref Kerk-geledere. Hierdie gevoel van besorgdheid moet egter binne 'n breër konteks gesien word. 
In die breë gesien, kan die Getuienis nie losgemaak word van die snelle ontwikkeling op kerklike, maatskaplike en politieke terrein aan die begin van die tagtigerjare in Suid-Afrika nie. In meer as een opsig kan hierdie snel veranderende tye as 'n oorgangsfase na 'n nuwe staatkundige en maatskaplike bedeling vir Suid-Afrika beskou word. Beide buitelandse en binnelandse omstandighede en ontwikkelinge gedurende die voorafgaande paar jare het verantwoording van kerk en owerheid gevra oor sy antwoorde op die eise en probleme van ons tyd. Die regering wat aan bewind was, het hierdie dringende vraag aangevoel en 'n redelike omvangryke konstitusionele gesprek het aan die gang gekom.

Die Getuienis was bedoel as 'n liefdevolle maar hoorbare verwoording van 'n bewoënheid oor die rol van die kerk te midde van die spanninge en polarisasie aan die begin van die tagtigerjare in Suid-Afrika. Dit is gepubliseer met die verwagting dat 'n biddende besinning sal realiseer oor die gaping wat soms bestaan tussen sinodebesluite en die uitvoering daarvan deur kerkrade en lidmate. Deur hierdie besinning sou onder andere die snel toenemende polarisasie moontlik besweer kon word, deurdat die kerk in hierdie era al meer die versoeningsinstument kan word wat hy onder meer bedoel is om te wees.

Die Getuienis self kan in drie onderdele verdeel word: eerstens die "waarom", tweedens die "waaroor" en derdens die "waartoe". In die "waarom" handel die agt ondertekenaars (proff C F A Borchardt, H J B Combrink, A B du Toit, W P Esterhuyse, J A Heyns, W D Jonker, B A Müller en H W Rossouw) oor die "skynbare onvermoë" van die kerk om sy roeping van versoening te vervul, om polarisasie te bekamp en die owerheid van 'n helder getuienis te bedien. Alhoewel daar in prinsipe moontlik nie sprake behoort te wees van so 'n onvermoë nie, toon die praktyk soms wel 'n "skynbare onvermoë". In die "waaroor" gaan dit oor die uitskakeling van liefdelose en rassistiese gesindhede, die christelike vereenselwiging met noodlydendes en oor die nastrewing van 'n groter mate van kerklike eenheid onder gelykbelydendes. Ten slotte gaan dit in die "waartoe" oor die bevordering van wedersydse vertroue en aanvaarding tussen die verskillende bevolkingsgroepe in Suid-Afrika, oor ' $n$ diepe bewussyn van die eise van Gods Woord tot hervorming van die bestaande orde en oor die getuienis dat die onderlinge verskille nie tot konflik nie, maar tot verryking kan dien.

Die agt teoloë het duidelik deur hul persoon, maar ook in die formulering van die Getuienis hul kritiese solidariteit en liefdevolle gesindheid teenoor die Ned Geref Kerk laat blyk, sodat daar nie twyfel behoort te bestaan oor die opregtheid van hul bedoelinge nie. Dit was ook 
allermins hul doel om die Ned Geref Kerk en die kerkleiding in die beskuldigdebank te plaas.

Die reaksie op die publikasie van die Getuienis was skerp, omvangryk en langdurig. Die hoofinhoud van die reaksie kan in drie strominge onderskei word. Sommige het hul geheel of gedeeltelik met die Getuienis vereenselwig. 'n Tweede groepering het die ondertekenaars daarvan beskuldig dat hulle 'n ongegronde, 'n oordrewe of 'n onrealistiese weergawe van die werklikheid voorgehou het. Veral is daarvan gewag gemaak dat die ondertekenaars met die uitdrukking "skynbare onvermoë" 'n ernstige refleksie op die kerk gewerp het, asof die kerk niks sou doen nie. Volgens sommige doen die kerk heeltemal genoeg. Dit bly egter 'n vraag of die verskil in standpunte oor hierdie aspek en selfs oor die hele getuienis nie wesenlik 'n verskil in die verstaan van die hele onderliggende werklikheid en probleemsituasie impliseer nie. ' $n$ Derde groepering het die Getuienis totaal probeer afmaak as 'n oefening in futiliteit, 'n afbrekende aksie of as maar net nog 'n verklaring met baie woorde en min dade.

Dat die Hervormingsdaggetuienis nie maar net as nog 'n verklaring afgemaak moet word nie, maar as 'n tipe waterskeiding aan die begin van die tagtigerjare beskou moet word, lyk vir my geregverdig. Opsigself was dit egter nie 'n absolute keerpunt nie.

Die nuwe era wat die Getuienis ingelei het, was een waarin die profetiese stem van die Ned Geref Kerk nog meer hoorbaar gemaak is. By baie geleenthede en op baie maniere het die Ned Geref Kerk sy profetiese roeping positief uitgeleef, onder andere ook via die Kommissie vir Skakeling met die Owerheid. Die Getuienis versinnebeeld egter vir baie Christene in die Ned Geref Kerk die begeerte om in die toentertydse tydsbedeling 'n nog breër en nog meer hoorbare profetiese stem te laat hoor, onder andere ook ten opsigte van die versoeningstaak van die kerk. En hieroor het Carl Borchardt ook sterk gevoel ${ }^{2}$.

Naas sy direkte betrokkenheid by die Hervormingsdaggetuienis was Borchardt ook redelik aktief in die Nasionale Inisiatief vir Versoening (NIV) wat deur Michael Cassidy van Africa Enterprise geïnisieer is. Borchardt se betrokkenheid was meer bepaald op streeksvlak en wel by die Pretoria Inisiatief vir Versoening (PIV). Hierdie organisasie, wat in die tagtigerjare ontstaan het, se visie was om nuwe Suid-Afrikaners vir 'n nuwe Suid-Afrika voor te berei. Die waarde van die menslike lewe is hoog aangeslaan. Aan mense en groepe is die nodige toerusting voorsien om ware versoening te realiseer. Verder is die Christen se betrokkenheid by vier kritiese areas geïdentifiseer: geweld en die vredesproses; die "verlore" geslag van swart jongmense; ekonomiese geregtigheid en 
demokrasie. Na die ingrypende veranderinge in Suid-Afrika na 2 Februarie 1990 en uiteindelik 27 April 1994 het die profiel van hierdie organisasie uiteraard laer geword3.

Carl Borchardt het nie net self 'n bydrae tot die Suid-Afrikaanse kerkgeskiedenis gelewer nie, maar hy het in sy hoedanigheid as stigterslid, jarelange algemene sekretaris en tans nog as president van die Kerkhistoriese Werkgemeenskap van Suidelike Afrika 'n reuse bydrae gelewer tot die uitbou van die kerkgeskiedenis as wetenskap in Suid-Afrika. Hy het nie net op sy stil manier andere aangemoedig om besig te raak of besig te bly met die beoefening van hierdie wetenskap nie, maar hy het voortdurend groot moeite gedoen en opofferinge gemak om via die werkgemeenskap 'n sinvolle infrastruktuur daar te stel vir die uitwisseling van gedagtes. Dit is dan ook een van die monumente wat Borchardt nalaat as teken van sy toewyding tot hierdie vakgebied. Op sestigjarige ouderdom is hy ook deur die Werkgemeenskap vereer toe enersyds 'n volledige uitgawe van die Werkgemeenskap se tydskrif naamlik Studia Historiae Ecclesiasticae aan hom opgedra is (waarin juis ook 'n hele aantal artikels aan die SuidAfrikaanse kerkgeskiedenis gewy is $)^{4}$ en andersyds die erelidmaatskap van die Werkgemeenskap aan hom toegeken is.

Borchardt het ook op ' $n$ onder meer indirekte manier 'n bepaalde bydrae tot die Suid-Afrikaanse kerkgeskiedenis gelewer. Alhoewel daar natuurlik etlike honderde studente beide by Unisa, maar ook by die Universiteit van Pretoria mede deur hom gevorm is, was daar twee studente by die Universiteit van Pretoria wat op gespesialiseerde doktorale vlak onder sy leiding voortgestudeer het, naamlik J W Claasen en $\mathrm{L}$ Ungerer. Claasen wat tans medeprofessor in die kerkgeskiedenis aan die Universiteit van Zoeloeland is, het onder Borchardt se promotorskap 'n proefskrif voorberei oor Die kerklik-godsdienstige agtergrond en invloed van die eerste Skotse leraars in Suid-Afrika. Ungerer, tans predikant van die Ned Geref Gemeente Monavoni het 'n proefskrif geskryf oor Die Ned Geref Kerk en die Wêreldbond van Gereformeerde Kerke.

\section{CARL BORCHARDT SE VISIE EN ARBEID OP DIE TERREIN VAN DIE SUID-AFRIKAANSE KERKGESKIEDENIS}

Alvorens 'n oorsig gebied word op Carl Borchardt se arbeid op die terrein van die Suid-Afrikaanse kerkgeskiedenis, is dit van belang om sy visie op hierdie vakgebied in die algemeen kortliks aan die orde te stel.

Borchardt voel sterk oor die teologiese karakter van hierdie vakgebied. Volgens hom moet die kerkhistorikus sigself afvra wat van die 
Evangelieboodskap tereg gekom het in die uitlê daarvan deur die eeue ${ }^{5}$ Hy stel dit egter ook duidelik dat die kerkhistorikus moet weet dat kerkgeskiedenis nie net van bo-af oor kerkleiers en sinodale besluite gaan nie, maar ook om die geskiedenis van onder-af, naamlik vanuit die oogpunt van die gewone lidmaat. Daarom beskou Borchardt ook briewe, dagboeke, persoonlike herinneringe, plaaslike kerklike brosjures en mondelinge bronne as belangrike bronne vir navorsing. Vir Borchardt is die relevansie van kerkgeskiedenis en by name die algemene kerkgeskiedenis van ewe groot belang juis ook vir die nuwe Suid-Afrika6.

Borchardt slaan die rol van kerkgeskiedenis in teologiese opleiding eweneens hoog aan. Geen persoon kan 'n suksesvolle predikant wees sonder om ook oor 'n goeie historiese agtergrond te beskik nie. Hy meen ook dat in die huidige bedeling kerkgeskiedenis van groot belang bly veral vanweë die bloeitydperk wat die ekumene tans beleef en sodat 'n mens ook kan weet hoe historiese gebeure die praktyk binne die kerk beïnvloed.

Borchardt slaan die taak om as kerkhistorikus interpretatief besig te wees, ook hoog aan. "In Kerkgeskiedenis gaan dit om interpretasie en daar kom steeds nuwe insigte na vore. Daarom sal daar steeds voortgegaan kan word met die vak want ons kry nooit klaar nie en die laaste woord sal nie duskant die wederkoms gespreek word nie" 7 .

Borchardt handel by geleentheid oor die relevansie van Luther se beroep op die Skrif alleen in die Afrika-konteks. Hy stel dat daar tans ook in Afrika ernstig geworstel word om die Skrifboodskap gestalte te gee in kerk en samelewing. Ten opsigte van die Ned Geref Kerk sê hy dat ten spyte van menslike feilbaarheid daar altyd gepoog is om rekenskap te probeer gee of besluite in ooreenstemming met die Skrif is. Hy voeg egter by: "Daar mag geoordeel word dat daar nie altyd suiwer na die Skrif geluister is nie byvoorbeeld in standpunte oor rasseverhoudinge of tydens die Rebellie... maar die kerk het altyd rekening probeer hou met die Skrif"8.

In vele opsigte verteenwoordig die bogenoemde styl en benadering nie net Borchardt se benadering tot die Suid-Afrikaanse kerkgeskiedenis op sigself nie, maar dit is selfs ook 'n samevatting van sy eie styl en lewensfilosofie: 'n mens wat erns maak met deeglike navorsing, 'n mens wat betrokke was by sy konteks en 'n mens wat in sy teologiese benadering egte kind van die Reformasie was.

Dit is nie vreemd dat Carl Borchardt hom hoofsaaklik instel op die Ned Geref Kerk wanneer hy 'n paar artikels en opstelle rondom die SuidAfrikaanse kerkgeskiedenis die lig laat sien nie. Dit is die kerk en die geskiedenis wat hy binne die Suid-Afrikaanse konteks die beste ken, maar 
wat hom ook die naaste aan die hart lè. Dit is vervolgens ook nie vreemd dat die spesifieke velde wat hy betree in hierdie artikels wentel rondom onderlinge kerklike verhoudinge oftewel ekumene en aan die ander kant samelewingskwessies nie. Ook dit was terreine waarin veral bydraes deur Carl Borchardt gelewer is.

In 1974 publiseer hy 'n artikel oor "Die betrekkinge tussen die drie Afrikaanse kerke 1886-1973" 9 . In hierdie artikel word aangedui hoe die drie Afrikaanse kerke in die periode met mekaar in verbinding getree het om oor hulle onderlinge verskille te praat en mekaar amptelik te erken. Hy volg die kerkhistoriese pad wat die drie kerke met mekaar gewandel het, besonder noukeurig. Hy beperk hom tot amptelike sinodale uitsprake alhoewel hy bewus is daarvan dat dit nie altyd 'n getroue weerspieëling is van onderlinge kontakte op gemeentelike en ander vlakke nie. Die volgende periodes kom ter sprake: kanselruil (1886-1899); kommissies van nouere vereniging (1903-1909); nuwe pogings van kontak tussen die Gereformeerde en Verenigde Kerke (1909-1916); kontak tussen die Verenigde en Hervormde Kerke (1928-1937); en die Tussenkerklike Kommissie. Ten slotte stel Borchardt dat na jare van misverstand en soms onwilligheid om mekaar te ontmoet "het die drie kerke gevorder vanaf daardie eerste versoek dat die predikante oor en weer mag preek, deur gesamentlike optrede in sosiale vraagstukke en mooi werk soos byvoorbeeld die Bybelvertaling, om mekaar uiteindelik te ontmoet en te konfereer oor dié dinge wat die drie Afrikaanse kerke skei. Na jare waarin hoofsaaklik gekonfereer is oor suiwer praktiese aangeleenthede, is die drie kerke nou besig met samesprekings en gedagtewisseling oor die belangrike en wesenlike vraagstukke soos ons siening oor die kerk en eenheid van die kerk"10.

In 1987 handel Borchardt in 'n artikel oor "Die Nederduitse Gereformeerde Kerk en die Suid-Afrikaanse Raad van Kerke"11. Hy verduidelik allereers die ontstaansgeskiedenis van die Suid-Afrikaanse Raad van Kerke (SARK) wat uit die Christenraad van Suid-Afrika ontwikkel het en hoedanig die aanvanklike verhouding tussen die Christenraad en die Ned Geref Kerk was. Daarna kom die spesifieke verhouding tussen die Ned Geref Kerk en die SARK ter sprake en veral soos dit blyk uit die standpunte var die verskillende Algemene Sinodes. Die Algemene Sinode van 1986 het uiteindelik weer besluit om informele samesprekinge met die SARK toe te laat wat deur Borchardt beskryf word as 'n "baie welkome klimaatsverandering in vergelyking met die sinodebesluit van 1982. Twee Christenliggame kon ten minste nou weer met mekaar praat"12. Borchardt draai geen doekies daarvoor om dat die 
SARK die grootste verteenwoordiger van die Kerk van Christus in SuidAfrika is nie en dat die Ned Geref Kerk, ten spyte van al die hindernisse nie kan bekostig om nie met die SARK te praat nie.

Aan die ander kant is Borchardt ook wel deeglik bewus en interpreteer hy dit ook as sodanig dat die Ned Geref Kerk baie pertinent produk van sy tyd was. Hy stel dit baie pertinent: “Die opkomende gety van Afrikaner-nasionalisme in die dertiger- en veertigerjare het 'n groot rol gespeel. Die handhawing van Afrikaans en 'n ander siening as die Engelse kerke ten opsigte van die rassekwessie het tot botsings gelei. Binne die Ned Geref Kerk was vanaf die veertiger- tot sestigerjare 'n hewige debat gevoer oor die Skriftuurlike regverdiging van sy rassebeleid" 13 .

Hy pleit ook vir 'n stuk realisme terwyl hy terselfdertyd kritiese vrae aan die adres van die Ned Geref Kerk rig: "Die agendas van die SARK het miskien ander beklemtonings as die agendas van die Ned Geref Kerk. Dit is waarskynlik te wyte aan die feit dat die Ned Geref Kerk 'n blanke kerk is en sy behoeftes in sommige opsigte anders is as die van swart mense". En dan vra hy: "Maar is hy nie daardeur armer en is sy visie op die Kerk van Christus nie meer beperk omdat hy net op homself (die blanke) toegespits is nie? Baie van die dinge wat die kerke uitmekaar hou, het nie te maak met die evangelie nie" 14 . Hy kom dan tot die gevolgtrekking dat die veranderende klimaat op politieke gebied waarskynlik die veranderde houding in die Ned Geref Kerk vergemaklik het. Die Afrikaner is deur die storm en drang periode van die veertigerjare, maar moet nou nuwe uitdagings die hoof bied.

In 1975 skryf Borchardt 'n artikel oor "Die Afrikaanse kerke en die Rebellie 1914-1915"15. In dié artikel wil hy die standpunte wat die Afrikaanse kerke ten opsigte van die Rebellie ingeneem het en soos dit uiteindelik in sinodale uitsprake verwoord is, ondersoek. Hy bied 'n kort historiese oorsig oor die Rebellie en die aard van die beweging waarna hy let op die houding van die Ned Geref Kerk, die Gereformeerde Kerk en die Nederduitsch Hervormde Kerk daarteenoor.

Borchardt haal $\mathrm{T} N$ Hanekom met instemming aan wanneer hy dit soos volg stel: "Dit is die kerk wat preek, maar dit is die Here wat moet spreek in daardie prediking. En as die kerk hierdie opdrag in die regte profetiese gees uitvoer, kan en sal dit ook gebeur dat hy meermale voor die plig te staan kom om nie net vir die volk nie, maar ook teen die volk te preek" 16 .

Redelik skerp en reguit is Borchardt se finale gevolgtrekking wanneer hy stel dat die kerk sekerlik nie alle rebelle voor die voet onder sensuur sou geplaas het nie, maar dat dit jammer is dat die kerke nooit 
gesê het dat wat die rebelle gedoen het, verkeerd was nie; verder ook dat die onderdaan nie met wapengeweld mag optree nie tensy die owerheid hom 'n opdrag daartoe gee waardeur hy voor die keuse gestel word om sy geloof te verloën. Met die Afrikaanse kerke het gebeur wat jammer genoeg ook op ander plekke in die kerkgeskiedenis voorgekom het: hulle het gepoog om na die hart van die volk te praat, maar daardeur het hulle ontrou geword as Kerk van Christus.

Alhoewel Borchardt huiwerig is om na 'n aantal dekades met 'n te skerp oordeel te kom, skryf hy die toedrag van sake beslis met reg toe aan die feit dat die kerk bang was vir 'n skeuring, dat hy graag vrede wou bewerk en dat hy nie in die politiek wou beland deur 'n uitspraak oor die Rebellie te maak nie.

In 1986 handel Borchardt in 'n opstel oor "Die 'swakheid van sommige' en die Sending"17. In hierdie oorsig handel hy oor die apartheidsteologie wat in die dertigerjare van die twintigste eeu sy beslag gekry het. Dit is egter voorafgegaan deur 'n aantal gebeure in die voorafgaande eeue van vestiging in Suid-Afrika. In die loop van hierdie tyd het verskeie belangrike beslissings geval wat ontwikkelinge sedert 1930 sterk beïnvloed het. Hy stel agtereenvolgens die eerste anderhalf eeu aan die orde, en dan die eerste sinodes, die sinode van 1857, die formulering van 'n sendingbeleid, en ten slotte 'n gevolgtrekking.

Hy kom uiteindelik tot die volgende slotsom: "Dit is jammer dat die Ned Geref Kerk nie bly weerstand bied het teen die groeiende neiging tot geskeidenheid tussen wit en swart in die kerk nie. Die kerk is immers 'n unieke gemeenskap, te wete kerk van God. Daarom moet, agterna besien, dit betreur word dat 'n toegewing in 1857 gemaak is aan die 'swakker broeders'. Die besluit van 1881 was noodlottig. Daarmee is een kerk verdeel in verskillende kerke, en onderlinge verkeer, waar kennis geneem kan word van mekaar se behoeftes en probleme, uitgeskakel. Hierdie sogenaamde 'geseënde beleid' is vandag die oorsaak dat ons langs mekaar in dieselfde land eintlik as vreemdelinge verby mekaar lewe" 18 .

\section{SLOT}

Carl Borchardt was by uitstek 'n deeglike en noukeurige navorser. Dis interessant dat hy in sy besigwees met die Suid-Afrikaanse kerkgeskiedenis hom waarskynlik vanweë praktiese redes veral op sinodale besluite beroep het. Soos vroeër in hierdie artikel aangedui, het hy egter ook geweet dat die kerkhistorikus hom steeds op 'n verskeidenheid van bronne moet beroep wat dagboeke, persoonlike herinneringe en mondelinge bronne insluit. 
Hy was verder 'n kerkhistorikus wat betrokke was, maar ook begrip gehad het vir 'n bepaalde konteks. Juis omdat hy 'n oop ekumeniese oog gehad het en self ook by kerk en samelewingsvraagstukke betrokke was, kon hy in sy teologiese interpretasie en beoordeling van gebeure altyd met 'n stuk versigtigheid, rustigheid en balans oordeel.

Vir Borchardt was die kernriglyn in sy besigwees met die kerkgeskiedenis deurentyd die vraag wat van die Evangelie-boodskap tereg gekom het in die uitlê daarvan ook in die Suid-Afrikaanse geskiedenis. Wanneer hy die Bybel en sy boodskap as norm aanwend, is sy visie daarop duidelik gereformeerd geïnspireerd.

Carl Borchardt het steeds 'n bepaalde sensitiwiteit vir die relevansie van historiese studies gehad. Dit het dan ook sy keuse van temas waarin hy hom verdiep het, tot op 'n sekere hoogte bepaal. Met goeie reg kan egter gestel word dat hy nooit geforseerd of propagandisties daarin was nie, want dit was vir hom grotendeels velde van intense belangstelling. Vir hom het dit gegaan oor verdere studie op hierdie terreine en nie oor 'n openbare standpunt wat hy wou stel nie. Hy wou die wetenskap help dien en nie sy eie saak nie.

Carl Borchardt het selde diepgaande teoretiese probleme rondom die kerkhistoriese wetenskap aangespreek. Hy het egter steeds die noukeurige navorser gebly wat baie spesifiek ekumenies en samelewingsgerig in sy benaderingswyse was. Behalwe dat hy die feite sterk laat spreek het, het hy steeds getrag om die stof teologies te interpreteer. In baie opsigte het Borchardt dus sterk in die voetstappe van sy Suid-Afrikaanse en Nederlandse leermeesters te wete B J Marais en J N Bakhuizen van den Brink gevolg, maar hy het ook vir homself 'n eie besondere staanplek in die kring van bekwame kerkhistorici in Suid-Afrika verower. Daarvoor eer ons hom graag.

\section{NOTAS:}

1 P B van der Watt (red.), Deo Gloria: Teologiese Fakulteit 1938-1988, Pretoria 1988,85 .

2 J W Hofmeyr, "Die Hervormingsdaggetuienis: 'n terugblik en evaluering”, Die Kerkbode, 4/11/1981, 8.

3 J W Hofmeyr, "Christianity in the South African context in a period of democratisation", Studia Historiae Ecclesiasticae 20/2 (1994), 115.

4 Studia Historiae Ecclesiasticae, 20/2 (1994). 
5 C F A Borchardt, Die beoefening van Algemene Kerkgeskiedenis in Suid-Afrika (Intreerede gelewer op 28 Februarie 1991 by die Universiteit van Pretoria), Pretoria 1991, 11.

6 Borchardt, $a w, 12$.

7 C F A Borchardt, “My jare by U.P.”, Deo Gloria 1994, 4.

8 C F A Borchardt, "Die relevansie van Luther se beroep op die Skrif alleen in Afrika-konteks, in: J W Hofmeyr en W S Vorster (reds.), New Faces of Africa, Pretoria 1984, 12.

9 C F A Borchardt, “Die betrekkinge tussen die drie Afrikaanse Kerke 18861973”, Ned Geref Teologiese Tydskrif 15/3 (1974), 181-203.

10 Borchardt, $a w, 203$.

11 C F A Borchardt, "Die Nederduitse Gereformeerde Kerk en die Suid-Afrikaanse Raad van Kerke", Skrif en Kerk 8/1 (1987), 1-19.

12 Borchardt, $a w, 15$.

13 Borchardt, $a w, 16$.

14 Borchardt, $a w, 17$.

15 C F A Borchardt, “Die Afrikaanse Kerke en die Rebellie 1914-1915", in: Teologie en Vernuwing (Onder redaksie van I H Eybers, A König, C F A Borchardt), Pretoria 1975, 85-116.

16 Borchardt, $a w, 113$.

17 C F A Borchardt, “Die 'swakheid van sommige' en die Sending”, in: Die N.G. Kerk en Apartheid (Onder redaksie van J. Kinghorn), Johannesburg 1986, 70 85.

18 Borchardt, $a w, 85$. 